Int. J. Dev. Biol. 55: 181-187 (2011)

doi: $10.1387 / \mathrm{ijdb} .103232 \mathrm{sm}$

\title{
Growth factor-defined culture medium for human mesenchymal stem cells
}

\author{
SUMIYO MIMURA ${ }^{1,2, \#, ~ N A O H I R O ~ K I M U R A ~}{ }^{3, \#, ~ M I T S U H I ~ H I R A T A ~}{ }^{1}$, DAIKI TATEYAMA ${ }^{1}$, \\ MIDORI HAYASHIDA ${ }^{1}$, AKIHIRO UMEZAWA ${ }^{4}$, ARIHIRO KOHARA ${ }^{1}$, HIROKI NIKAWA $^{2}$, \\ TETSUJI OKAMOTO ${ }^{3}$ and MIHO K. FURUE*,1

\begin{abstract}
${ }^{1}$ JCRB Cell Bank, Laboratory of Cell Cultures, Department of Disease Bioresources, National Institute of Biomedical Innovation, Osaka, ${ }^{2}$ Department of Oral Biology and Engineering, Division of Oral Health Science, Graduate School of Biomedical Sciences, Hiroshima University, Hiroshima, ${ }^{3}$ Department of Pathology, National Research Institute for Child Health and Development, Tokyo, Japan
\end{abstract} \\ Molecular Oral Medicine and Maxillofacial Surgery, Division of Frontier Medical Science, Graduate School \\ of Biomedical Sciences, Hiroshima University, Hiroshima and ${ }^{4}$ Department of Reproductive Biology and
}

\begin{abstract}
Human bone marrow-derived mesenchymal stem cells (hMSCs) are potential cellular sources of therapeutic stem cells as they have the ability to proliferate and differentiate into a wide array of mesenchymal cell types such as osteoblasts, chondroblasts and adipocytes. hMSCs have been used clinically to treat patients with graft vs. host disease, osteogenesis imperfect, or alveolar cleft, suggesting that transplantation of hMSCs is comparatively safe as a stem cell-based therapy. However, conventional culture medium for hMSCs contains fetal bovine serum (FBS). In the present study, we developed a growth factor-defined, serum-free medium for culturing hMSCs. Under these conditions, TGF- $\beta 1$ promoted proliferation of hMSCs. The expanded hMSC population expressed the human pluripotency markers SSEA-3, -4, NANOG, OCT3/4 and SOX2. Furthermore, double positive cells for SSEA-3 and a mesenchymal cell marker, CD105, were detected in the population. The potential to differentiate into osteoblasts and adipocytes was confirmed. This work provides a useful tool to understand the basic biological properties of hMSCs in culture.
\end{abstract}

KEY WORDS: mesenchymal stem cell, serum-free culture, TGF- $\beta 1$

\section{Introduction}

Bone marrow-derived cells can differentiate into osteoblasts in vitro and in vivo (Friedenstein et al., 1966) and thus are considered a useful source of stem cells for bone regeneration. Recently, many studies have reported that human bone marrow contains a distinct cell fraction referred to as multipotent mesenchymal stem cells (hMSCs) which can give rise to a wide array of mesenchymal cell types, including bone, fat, and cartilage"(Pittenger et al., 1999). However, hMSCs can differentiate along some ectodermal and endodermal cell lineages such as neuronal cells and liver cells (Pittenger et al., 1999; Dezawa et al., 2004; Dezawa et al., 2005). Further, a recent study reported that hMSCs have the ability to generate the multiple cell types derived from the three embryonic germ layers (Kuroda et al.,
2010). It has been estimated that hMSCs comprise about 0.001 to $0.01 \%$ of total bone marrow mononuclear cells (Pittenger et al., 1999). For use in cell-based therapies, hMSC populations require extensive in vitro expansion to obtain sufficient numbers. The conventional culture medium for hMSCs is composed of a basal nutrient medium supplemented with fetal bovine serum (FBS) (Haynesworth et al., 1992; Lennon DP, 1996). Although these traditional culture conditions provide robust undifferentiated hMSC expansion, the ill-defined components of FBS is undesirable for clinical applications and also hampers analysis of the cell biological mechanisms that control cell behavior.

Abbreviations used in this paper: hES cells, human embryonic stem cells; hMSCs, human mesenchymal stem cells.

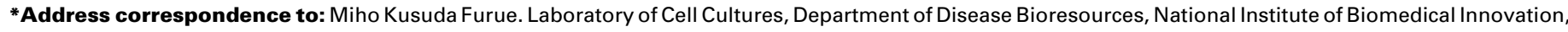

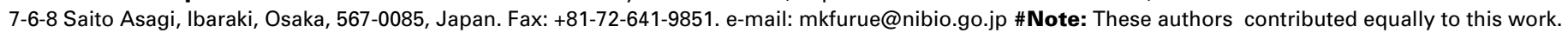

Supplementary Material (3 tables) for this paper is available at: http://dx.doi.org/10.1387/ijdb.103232sm

Accepted: 9 September 2010. Final author corrected PDF published online: 3 February 2011. Edited by: Makoto Asashima.

ISSN: Online 1696-3547, Print 0214-6282

(c) 2011 UBC Press

Printed in Spain 
We and others previously described serum-free media consisting of minimum essential components suitable to propagate and accurately analyze the characteristics of differentiated cells (Hayashi and Sato, 1976; Furue and Saito, 1998; Sato et al., 2002; Furue et al., 2005; Furue et al., 2008; Hayashi et al., 2010). One of these media, hESF9, supports the serial cultivation of undifferentiated human embryonic stem (hES) cells in the absence of feeder cells and thus provides an experimental system for elucidating cellular responses to specific environmental stimuli (Furue et al., 2008; Na et al., 2010). For example, either FGF-2 or heparin promotes proliferation of hES cells in a concentrationdependent manner although these effects were not detected under conventional culture conditions. Thus, a defined serumfree medium consisting of minimum essential components should be useful in elucidating hES/iPS cell responses to specific cues that control self-renewal, differentiation, and lineage selection (Furue et al., 2010).

Because hMSCs have multipotent properties similar to hES cells, we speculated that hMSCs should be able to grow in similar culture conditions as hES cells. In the present study, we demonstrated that addition of TGF- $\beta 1$ to the defined serum-free medium for hES cells supports the robust proliferation of hMSCs. The hMSC population expanded in the absence of serum expressed the mesenchymal cell markers CD44, CD73, CD90, and CD105. Further, they expressed human pluripotency surface markers, SSEA-3, -4, TRA-2-54, and also the transcription factors of NANOG, OCT3/4, and SOX2. We show that the serum-free expanded hMSCs can differentiate into osteoblasts and adipocytes. This work sets the stage for serum-free hMSC cell culture and thereby provides a useful tool to understand the basic biological characteristics of hMSCs.

\section{Results}

In this study we used a human bone marrow-derived hMSC line designated UE7T-13 (JCRB 1154). The life span of these cells was prolonged by infecting them with a retrovirus containing human papillomavirus E7 and telomerase reverse transcriptase (hTERT) cDNAs (Mori et al., 2005; Shimomura et al., 2007; Ishii et al., 2008; Takeuchi et al., 2007). We first tested the ability of hESF9 medium, which we had developed for use with hES cells, to support the growth of UE7T-13 cells. The cells were harvested using trypsin/EDTA, from cultures in conventional medium containing 10\% FBS (POWERDBY10) and transferred to $0.1 \%$ gelatin-coated dishes in hESF9 medium. However, UE7T-13 cell growth was quite slow. We then investigated the effects of various growth factors on proliferation of the cells. UE7T-13 cells were seeded on $0.1 \%$ gelatin in hESF9 in the absence of FGF-2 and heparin (hESF9(-/-)), containing increasing concentrations of FGF-1, FGF-2, TGF- $\beta 1$, activin A, or leukemia inhibitory factor (LIF) (Fig. 1). Both FGF-1 and FGF2 promoted UE7T-13 proliferation in a dose-dependent manner, and the greatest effect was seen at $10 \mathrm{ng} / \mathrm{ml}$ FGF-2. Neither LIF nor activin A affected on UE7T-13 cell proliferation, but TGF- $\beta 1$ slightly stimulated UE7T-13 proliferation. Next all five factors (FGF-1, FGF-2, TGF- $\beta 1$, activin $A$, and LIF) or four factors with increasing concentrations of heparin were added to UE7T-13 cultures (Fig. 2). When either FGF-2 or TGF- $\beta 1$ was withdrawn from the cultures, the cell numbers decreased significantly. Heparin promoted cell proliferation in a dose-dependent manner. This result suggested that addition of FGF-2 and TGF- $\beta 1$ to hESF9(-/-) medium, is critical for UE7T-13 proliferation, and heparin also enhanced cell growth. hESF9 medium supplemented with TGF- $\beta 1$ was designated hESF10.

L-ascorbic acid-2-phosphate (Asc 2-P) in hESF9 medium supported hES cells. However, it is known to promote hMSC cell differentiation into osteoblasts. Therefore, we examined whether the presence of Asc 2-P in hESF10 medium promoted osteoblastic differentiation of UE7T-13 cells. We analyzed the expression of bone sialoprotein (IBSP), osteocalcin (BGP), osteonectin (SPOCK2), and osteopontin (SPP1) in UE7T-13 cell cultured in hESF10 with or without Asc 2-P and in conventional medium (Fig. 2). These osteoblast genes were expressed at significantly lower levels in cells cultured in the serum-free media than in those cultured in the conventional medium. These results suggest that the serum-free medium is suitable for hMSC maintenance. IBSPgene expression was higher in the cells cultured in the
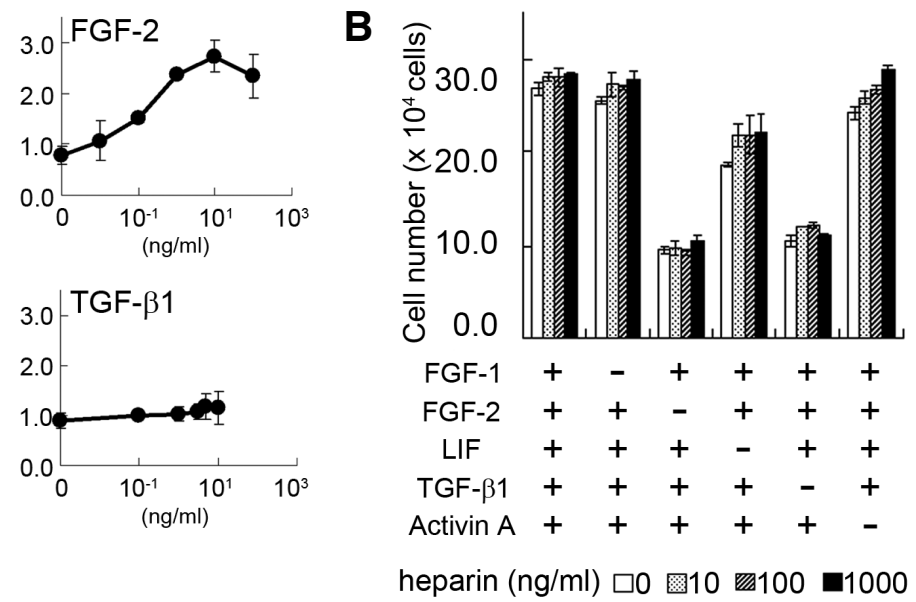

Fig. 1. Effect of growth factors on UE7T-13 cell proliferation in defined serum-free culture conditions. After the UE7T-13 cell grown in the conventional culture conditions (POWERDBY10) were cultured in hESF9(--) overnight, the cells were seeded in a 24-well plate coated $0.1 \%$ gelatin in hESF9(-/-) at 1 $\times 10^{4}$ cells per well and cultured for 6 days. The cell numbers were counted by Coulter Counter. (A) Each growth factor at indicated concentration was added into each well individually. The values are the mean $\pm S D(n=3)$. (B) All five factors of FGF-1 (100 ng/ml), FGF-2 (10 ng/ml), LIF (2000 unit/ml), TGF- $\beta 1$ (5 $\mathrm{ng} / \mathrm{ml})$, and activin A $(10 \mathrm{ng} / \mathrm{ml})$ or four factors of them with varying concentration of heparin were added into each well. The values are the mean $\pm S D(n=3)$. 
presence of Asc 2-P. These results suggested that Asc 2-P promoted differentiation of UE7T-13 cells into osteoblasts. We removed Asc 2-P from hESF10 medium for hMSCs, and designated the new formulation D-hESF10.

To confirm the characteristics of UE7T-13 cells expanded in the absence of serum, we performed flow cytometry with antibodies to markers for hMSCs and pluripotent cells (Fig. 3A). Cells grown in D-hESF10 medium were positive for CD44, CD73, CD90, CD105, and TRA-2-54 (tissue non-specific alkaline phosphatase antibody), but negative for CD45 (a marker of all hematopoietic cells) and CD56 (a neural cell adhesion molecule). We further stained the cells with antibodies to CD105 and SSEA-3 (Fig. 3B). The immunocytochemical analysis showed that SSEA $-3^{+} /$CD $105^{+}$double positive cells were present in the UE7T-13 population grown in D-hESF10 although cells positive for either CD105 or SSEA-3 were also detected in the population. The cell growth rate in D-hESF10 was comparable to that in conventional culture conditions (Fig. 4).

We subsequently examined the properties of UE7T-13 cells serially passaged in D-hESF10 medium. The morphology of serum-free expanded UE7T-13 cell populations was comparably small, spindle-shaped cells compared with that in conventional medium (Fig. 5A). The expression of hMSC and hES cell pluripotency markers were determined by real-time PCR analysis (Fig. 5B) in UE7T-13 cells cultured for 4 passages in D-hESF10 medium. The expression of hMSC markers, CD105, THY1, and integrin $\beta 1$ (/TGB1), and the hES cell pluripotency markers, OCT3/4 (POU5F1) and NANOG were similar in the cells cultured in D-hESF10 compared with those in the cells cultured in conventional culture conditions. SOX2 expression was significantly higher in cells cultured in D-hESF10 compared with cells cultured in conventional culture conditions. On the other hand, the expression levels of IBSP, BGP, SPOCK2, and SPP1 were significantly lower in cells cultured in $D$ hESF10 compared with those in the cells cultured in conventional culture conditions. These results suggest that serum-free expanded UE7T-13 cells retain an undifferentiated phenotype.

We determined the differentiation capacity of the serum-free expanded UE7T-13 cells. After the UE7T-13 cells were cultured in D-hESF10 for 7 passages, the cells were cultured in medium designed to induce differentiation into osteoblasts or adipocytes (Fig. 6). Culturing in osteoblastic differentiation medium induced the formation of nodules that stained positive with Alizarin red, suggesting that the cells had the potential to differentiate into osteoblasts. When the cells were cultured in
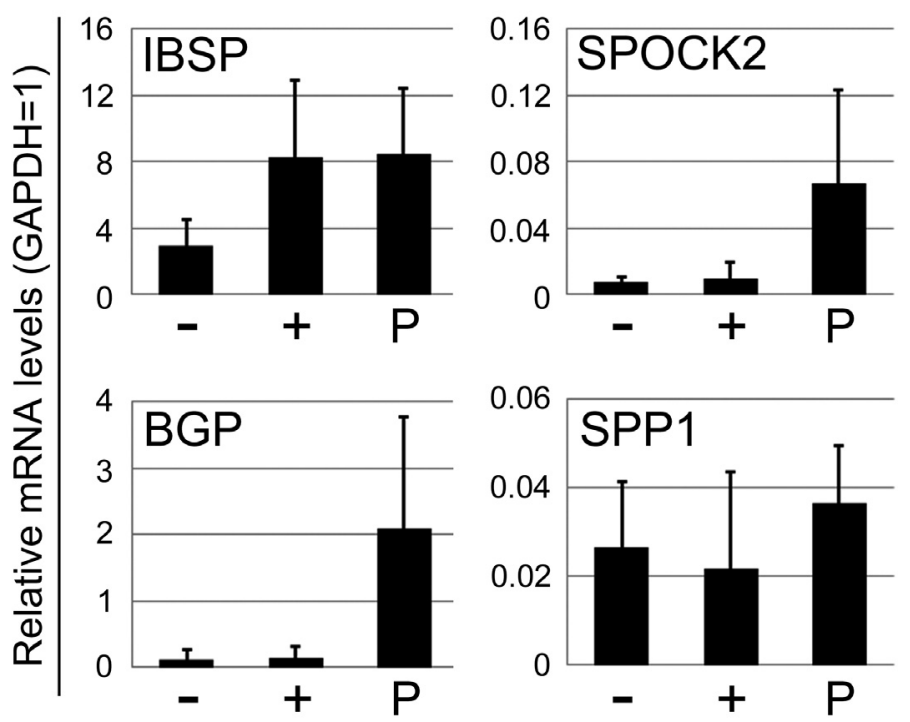

Fig. 2 (above). The effect of culture conditions on osteoblastic marker expression. The gene expression in the cells cultured on gelatin in hESF10 without (-) or with (+) Asc 2-P for 6 days, in comparison with the cells grown in POWERDBY10 (P) was analyzed by the quantitative $R T-P C R$. The gene expression was normalized by the amount of GAPDH. The values are the mean $\pm S D(n=3)$.
A
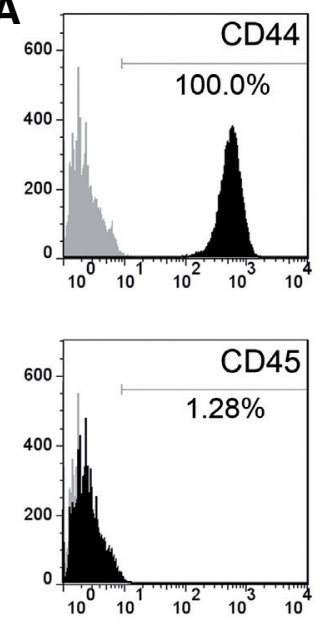
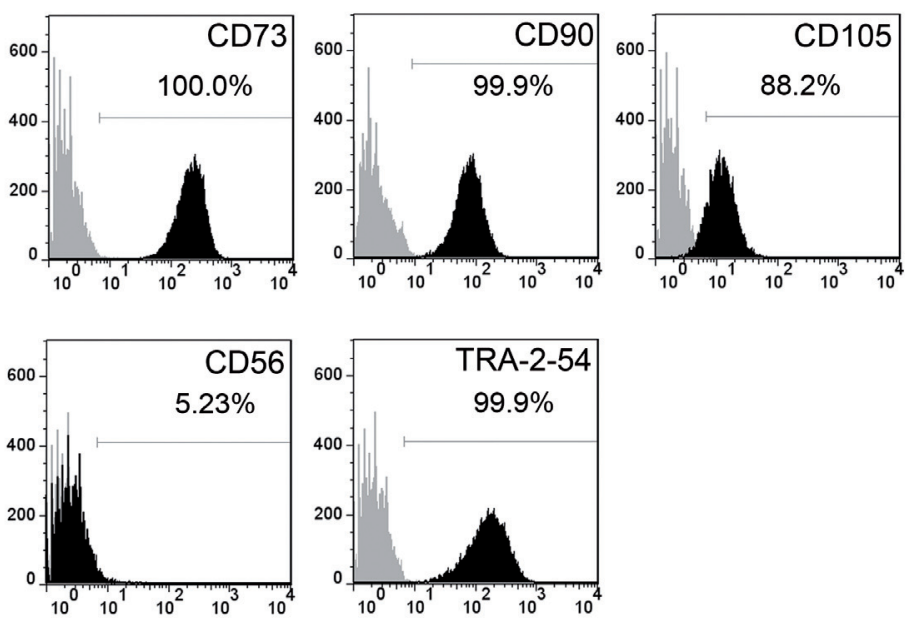

B Hoechst

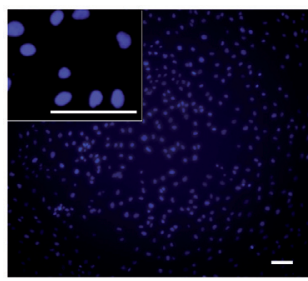

CD105

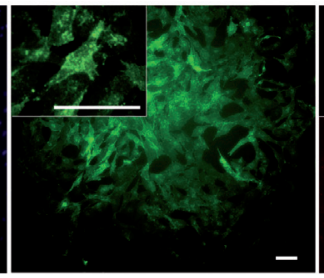

SSEA-3

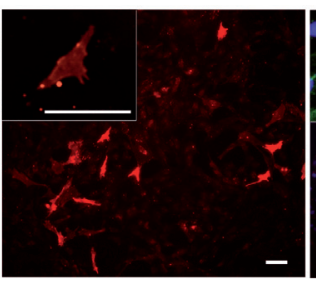

Merged

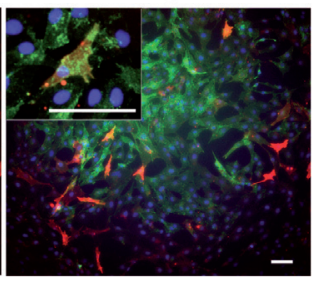

Fig. 3. Expression of hMSC markers in UE7T-13 cells. (A) Flow cytometric profiles for CDs in UE7T13 cells. hMSC marker expression in UE7T-13 cells cultured on gelatin in D-hESF10 for 4 days was analyzed by flow cytometric analysis. Antigen histogram (black); control histogram (gray); the horizontal bar indicates the gating used to score the percentage of antigen-positive cells. (B) Immunocytochemical analysis of SSEA-3 and CD105 expression in UE7T-13 cells cultured on gelatin in D-hESF10 for 4 days. Scale bars, $100 \mu \mathrm{m}$. 


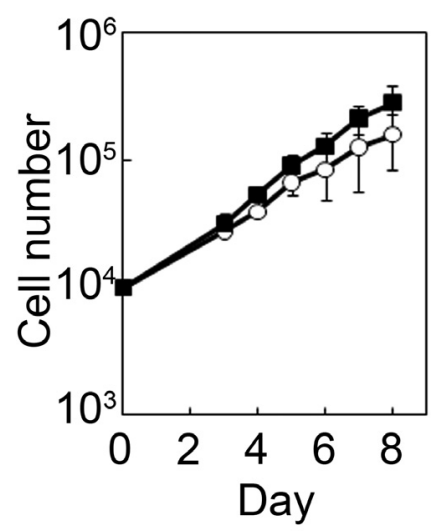

A

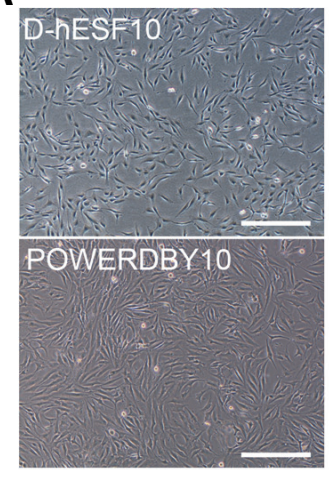

Fig. 4 (above left). A comparison of the growth of different UE7T- 13 cells in the defined serum-free medium and conventional culture conditions. The cells were seeded in a 24-well plate coated with gelatin in D-hESF10 (open circle), or in a 24-well plate in POWERDBY10 (closed square) at a cell density of $1 \times 10^{4}$ cells per well. Cell numbers were counted every day. The values are the mean $\pm S D(n=3)$.

adipocytic differentiation medium, Oil red O-positive cells appeared. Taken together these results suggest that the serum-free expanded UE7T- 13 cells have maintained the capacity to differentiate into osteoblasts or adipocytes.

\section{Discussion}

Developing clinical serum-free media for maintaining and expanding human stem cells is a major research topic in regenerative medicine. Our current results indicate that it is possible to culture hMSCs on gelatin in a defined medium, designated D-hESF10, in which human recombinant insulin, human transferrin, a low concentration of fatty acid-free bovine albumin conjugated with oleic acid, FGF-2, and TGF- $\beta 1$ are the protein components. The basal medium ESF was developed for mouse ES cells (Furue et al., 2005). For hES cell culturing, N-2-hydroxyethylpiperazine-N'-2ethane-sulfonic acid (HEPES) was removed from ESF but Asc 2-P was added (Furue et al., 2008). For propagating hMSCs, Asc 2-P was removed from the $\mathrm{hES}$ cell culture medium because we found that Asc 2-P increased osteoblastic marker expression in $\mathrm{hMSCs}$. These findings indicated that signaling by Asc 2-P in hMSCs is different from that in hES cells.

FGF-2 is a heparin-binding growth factor which stimulates the proliferation of a wide variety of cells. The biological activity of FGF-2 is efficient in the concentration range of 0.1 to $10.0 \mathrm{ng} / \mathrm{ml}$. Addition of FGF-2 has been shown to increase the growth rate and life span of hMSCs from different species (Tsutsumi et al., 2001; Benavente et al., 2003), suggesting that FGF-2 play an important role in self-renewal of hMSCs. In hES cells, FGF-2 is a crucial to maintain the undifferentiated state (Amit et al., 2004; Hoffman and Carpenter, 2005). We previously reported that FGF-2 at $10 \mathrm{ng} / \mathrm{ml}$ together with heparin supported the cell proliferation of $h E S$ cells in serum-free without feeders (Furue etal., 2008). In this study, we found that FGF-2 at $10 \mathrm{ng} / \mathrm{ml}$ together with heparin supported the cell proliferation of hMSCs in a serum-free medium. These findings suggest that they share the same signal pathway to
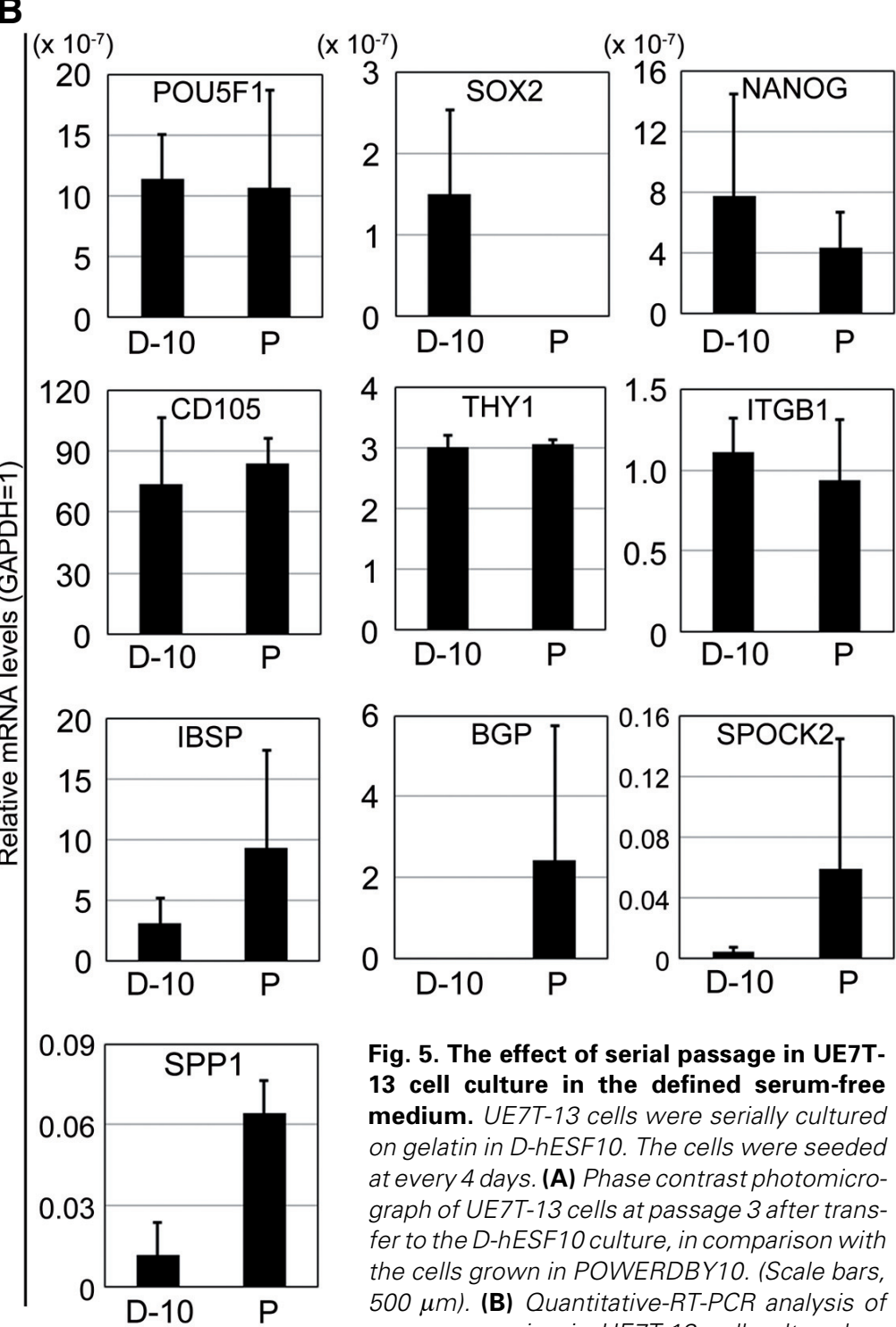

Fig. 5. The effect of serial passage in UE7T13 cell culture in the defined serum-free medium. UE7T-13 cells were serially cultured on gelatin in D-hESF10. The cells were seeded at every 4 days. (A) Phase contrast photomicrograph of UE7T- 13 cells at passage 3 after transfer to the D-hESF10 culture, in comparison with the cells grown in POWERDBY10. (Scale bars, $500 \mu \mathrm{m})$. (B) Quantitative-RT-PCR analysis of gene expression in UE7T-13 cell cultured on gelatin in D-hESF10 at passage 4 (D-10), in comparison with the cells grown in POWERDBY10 (P). The name of each gene is noted in each bar graph. Gene expression was normalized with respect to GAPDH. The values are the mean $\pm S D(n=3)$.

support self-renewal. Heparin at $1 \mathrm{mg} / \mathrm{ml}$ promoted $\mathrm{hMSC}$ cell proliferation, and we previously reported that heparin at $1 \mathrm{mg} / \mathrm{ml}$ inhibited $\mathrm{hES}$ cell proliferation. Thus the sensitivity to heparin is different between hMSCs and hES cells.

The TGF- $\beta 1$ pathway has been reported to be important in hMSC differentiation into the osteogenic and chondrogenic lineages ( $\mathrm{Li}$ and $\mathrm{Xu}, 2005$; Kulterer et al., 2007). While we have shown that TGF- $\beta 1$ alone did not promote cell proliferation of hMSCs, the combination with FGF-2 and heparin enhanced cell proliferation of hMSCs. Chase et al. reported the combination of TGF- $\beta 1$, FGF-2, and PDGF-BB in a commercial serum-free medium for the expansion of hMSCs although the optimal concentrations of these factors were not disclosed. The cell growth rate in D-hESF10 medium was similar with that in the conven- 
tional culture conditions suggesting that addition of TGF- $\beta 1$ and FGF-2 is sufficient to replace serum in supporting hMSC cell growth. A culture medium consisting of the minimum components necessary to support survival and proliferation would be beneficial to understand the characteristics of naïve hMSCs. Therefore, we think that addition of PDGF-BB is not crucial for an hMSC culture medium.

Several studies reported that two distinct cell morphologies are seen in early-passage hMSC cultures: small, spindle-shaped cells that are rapidly self-renewing and large, flat cells that replicate slowly and appear more mature (Mets and Verdonk, 1981; Colter et al., 2001; Sekiya et al., 2002). The morphology of serum-free expanded UE7T-13 cell population contained comparably small, spindle-shaped cells. However, specific undifferentiated markers of hMSCs have not been identified yet (Pochampally et al., 2004). Further, although the cells are cloned, cells within an individual colony are heterogeneous in morphology, growth rates, and efficiency with which they differentiate (Mets and Verdonk, 1981; Bruder et al., 1997; Colter et al., 2001). The International Society for Cellular Therapy (ISCT) has proposed three criteria to define hMSCs (Dominici et al., 2006). hMSC population must be positive at least for several antigens such as CD105, CD73, and CD90, and negative for CD45. CD105 is usually used to identify an hMSC population. Many studies reported that hMSCs also expressed hES cell pluripotency markers, SSEA-3, -4, NANOG, OCT3/4, and alkaline phosphatase (Pochampally et al., 2004; Roubelakis et al., 2007; Battula et al., 2008; Conrad et al., 2008; Pang et al., 2010). We also detected the expression of NANOG, OCT3/4, and SOX2. These findings suggested that hES cell pluripotency markers may be universal stem cell markers in humans. Dezawa's group recently reported that double positive CD105 and SSEA-3 cells have the ability to generate multiple cell types derived from the three embryonic germ layers (Kuroda et al., 2010). We also confirmed the existence of CD105 and SSEA3 double positive cells in the hMSC population expanded in DhESF10. In this stıidy, we confirmed the differentiation potential of hMSCs to generate osteoblasts or adipocytes, but in the future we will examine the ability of hMSCs to generate cells from all three germ layers.

To facilitate the transition of human stem cell biology from basic research to clinical application all the components of maintenance and differentiation media should be publicly disclosed so

Fig. 6. The differentiation ability of UE7T-13 cell grown in the defined medium. The UE7T-13 cells were serially cultured in D-hESF10 at passage 7 , and then cultured in the differentiation medium. (A) Osteoblastic differentiation was induced in osteoblastic medium for 20 days. The nodules were stained with Alizarin Red $S$ (red). (B) Adipocytic differentiation was induced in adipocytic medium for 24 days. The cells were stained by Oil red O staining (red). Scale bars: $500 \mu \mathrm{m}$. they can be evaluated by many researchers. A commercial xenofree serum-free medium for hMSCs was reported recently (Chase et al., 2010). However, the non-disclosure of components is problematic as the medium formulation cannot be usefully modified or improved. Because all the components of D-hESF10 medium are disclosed here, the medium can be modified to study signaling pathways involved in maintaining multipotency and to develop differentiation protocols.

\section{Materials and Methods}

\section{Cell Cultures}

An immortalized hMSC line UE7T-13 (Mori et al., 2005) (JCRB 1154, JCRB Cell Bank, Osaka, Japan) was used in this study. Cells were maintained on $100 \mathrm{~mm}$ dish (BD Falcon, Oxnard, CA) in POWERDBY10 (MED-SHIROTORI, Tokyo, Japan) that was also used in the experiments as a control medium. The cells were harvested with $0.25 \%$ trypsin in $1 \mathrm{mM}$ EDTA-4Na.

\section{Serum-free Cell Culture Media}

hESF9 comprises ESF basal medium (Furue et al., 2005) without HEPES supplemented with nine defined factors: Asc 2-P, 6-factors (human recombinant insulin, human transferrin, 2-mercaptoethanol, 2ethanolamine, sodium selenite, oleic acid conjugated with fatty acid-free bovine serum albumin (FAF-BSA)), bovine heparan sulfate sodium salt, and human recombinant FGF-2 (Sigma, St. Louis, MO), as described previously (Furue et al., 2008) (Supplementary Table 1). ESF basal medium without HEPES supplemented with Asc 2-P (hESF-GRO), and ESF basal medium without HEPES and Asc 2-P (hESF-DIF) were purchased by the Cell Science \& Technology Institute (CSTI, Sendai, Japan). All other reagents were from Invitrogen (Carlsbad, CA) and Sigma. D-hESF10 medium consists of hESF-DIF medium supplemented with 6-factors, FGF-2, heparin, and TGF- $\beta 1$ (R\&D Systems, Minneapolis, $\mathrm{MN})$. To harvest cells, $0.25 \%$ trypsin in $1 \mathrm{mM}$ EDTA-4Na was used and the trypsin was inactivated with $0.1 \%$ soybean trypsin inhibitor (Sigma). For differentiation into osteoblasts or adipocytes, the cells were cultured according to the instruction by the suppliers (Lonza, Basel, Switzerland). The differentiated cells were stained by Alizarin Red S (Wako Pure Chemical Industries, Osaka, Japan) or Oil Red O (Wako).

\section{Cell proliferation}

Before the serum-free experiments, cells grown in POWERDBY10 were incubated by in hESF9 medium without heparin and FGF-2 (hESF9(-/-)) overnight to starve the effect of serum. Cells were replaced at the cell density of $1 \times 10^{4}$ cells /well on 24-well plate (BD Falcon) coated with $0.1 \%$ porcine gelatin solution (Millipore, Billerica, MA) and cultured in hESF9(-/-) medium in the presence of varying growth factors. The cell numbers were counted by Coulter Counter (Beckman Coulter, Hialeah, FL).

\section{Gene expression}

A detailed reverse transcription-polymerase chain reaction (RT-PCR) protocol was described previously (Furue, et al., 2005). Total RNA was extracted from hMSCs using RNeasy Mini Kit (Qiagen, Hilden, Germany) and SuperScript VILO cDNA Synthesis Kit (Invitrogen) according to the provider's instructions. Q-RT-PCR was carried out using the TaqMan gene expression Master Mix on in ABI PRISM 7300 Real-Time PCR system (Applied Biosystems, Foster City, CA) according to the supplier's instructions $(A B I)$. Specific primers-probe set were listed in Supplementary Table 2. Expression levels were all normalized by the expression level of GAPDH. The relative level of each gene in cDNA of undifferentiated hES cells was defined as "1." The KhES-3 cell line was used as a control; the cells were obtained from the Institute for Frontier Medical Science, Kyoto University, and the Review Board of the National Institute of Biomedical Innovation approved this research. 


\section{Antigen expression}

For in situ immunocytochemisty, the cells were immunostained with antibodies, as described previously (Draper et al., 2002; Furue et al., 2008). In this study, fluorescence images were acquired using by IN Cell Analyzer 2000 (GE Healthcare, Buckinghamshire, England). Flow cytometry was performed with BD FACS Canto flow cytometer (Becton Dickinson, San Jose, CA) as described previously (Draper et al., 2002; Furue et al., 2008). In this study, the labeled primary antibodies were used, but the biding of anti-SSEA-3, anti-CD56, and Tra-2-54 antibodies was visualized with RPE-conjugated goat anti-mouse lg (Dako, Carpinteria, CA) or Alexa Fluor 647 goat anti-rat IgM (Invitrogen). The primary antibodies used are listed in Supplementary Table 3.

\section{Acknowledgements}

We thank Prof. Peter W. Andrews for the generous gift of anti-SSEA3 and Tra-2-54 antibodies, and we thank Dr. J. Denry Sato for editorial assistance. We also thank Dr. Masaki Kinehara, Azusa Ohtani, Eiko Kawaguchi, Yutaka Ozawa, Hiroko Matsumura, Tomoko Hirayama, and Setsuko Shioda for excellent technical advice. This study was supported by grants-in-aid from the Ministry of Health, Labor and Welfare of Japan to M.K.F. and A.K., and by grants-in-aid for Scientific Research from the Ministry of Education, Culture, Sports, Science and Technology of Japan to M. K.F. and T.O.

\section{References}

AMIT, M., SHARIKI, C., MARGULETS, V. and ITSKOVITZ-ELDOR, J. (2004). Feeder layer- and serum-free culture of human embryonic stem cells. Biol Reprod70: 837-845.

BATTULA, V.L., TREML, S., ABELE, H. and BUHRING, H.J. (2008). Prospective isolation and characterization of mesenchymal stem cells from human placenta using a frizzled-9-specific monoclonal antibody. Differentiation 76: 326-336.

BENAVENTE, C.A., SIERRALTA, W.D., CONGET, P.A. and MINGUELL, J.J. (2003). Subcellular distribution and mitogenic effect of basic fibroblast growth factor in mesenchymal uncommitted stem cells. Growth Factors 21: 87-94.

BRUDER, S.P., JAISWAL, N. and HAYNESWORTH, S.E. (1997). Growth kinetics, self-renewal, and the osteogenic potential of purified human mesenchymal stem cells during extensive subcultivation and following cryopreservation. J Cell Biochem 64: 278-294.

CHASE, L.G., LAKSHMIPATHY, U., SOLCHAGA, L.A., RAO, M.S. and VEMURI, M.C. (2010). A novel serum-free medium for the expansion of human mesenchymal stem cells. Stem Cell Res Ther 1: 8.

COLTER, D.C., SEKIYA, I. and PROCKOP, D.J. (2001). Identification of a subpopulation of rapidly self-renewing and multipotential adult stem cells in colonies of human marrow stromal cells. Proc Nat/ Acad Sci USA 98: 7841-7845.

CONRAD, C., ZEINDL-EBERHART, E., MOOSMANN, S., NELSON, P.J., BRUNS, C.J. and HUSS, R. (2008). Alkaline phosphatase, glutathione-S-transferase-P, and cofilin-1 distinguish multipotent mesenchymal stromal cell lines derived from the bone marrow versus peripheral blood. Stem Cells Dev 17: 23-27.

DEZAWA, M., ISHIKAWA, H., ITOKAZU, Y., YOSHIHARA, T., HOSHINO, M., TAKEDA, S., IDE, C. and NABESHIMA, Y. (2005). Bone marrow stromal cells generate muscle cells and repair muscle degeneration. Science 309: 314-317.

DEZAWA, M., KANNO, H., HOSHINO, M., CHO, H., MATSUMOTO, N., ITOKAZU, Y., TAJIMA, N., YAMADA, H., SAWADA, H., ISHIKAWA, H. et al. (2004). Specific induction of neuronal cells from bone marrow stromal cells and application for autologous transplantation. J Clin Invest 113: 1701-1710.

DOMINICI, M., LE BLANC, K., MUELLER, I., SLAPER-CORTENBACH, I., MARINI, F., KRAUSE, D., DEANS, R., KEATING, A., PROCKOP, D. and HORWITZ, E. (2006). Minimal criteria for defining multipotent mesenchymal stromal cells. The International Society for Cellular Therapy position statement. Cytotherapy 8: 315-317.

DRAPER, J.S., PIGOTT, C., THOMSON, J.A. and ANDREWS, P.W. (2002). Surface antigens of human embryonic stem cells: changes upon differentiation in culture. J Anat 200: 249-258.
FRIEDENSTEIN, A.J., PIATETZKY, S., II and PETRAKOVA, K.V. (1966). Osteogenesis in transplants of bone marrow cells. J Embryol Exp Morphol 16: 381 390.

FURUE, M., OKAMOTO, T., HAYASHI, Y., OKOCHI, H., FUJIMOTO, M., MYOISHI, Y., ABE, T., OHNUMA, K., SATO, G.H., ASASHIMA, M. et al. (2005). Leukemia inhibitory factor as an anti-apoptotic mitogen for pluripotent mouse embryonic stem cells in a serum-free medium without feeder cells. In vitro Cell Dev Biol Anim 41: 19-28.

FURUE, M.K., NA, J., JACKSON, J.P., OKAMOTO, T., JONES, M., BAKER, D., HATA, R., MOORE, H.D., SATO, J.D. and ANDREWS, P.W. (2008). Heparin promotes the growth of human embryonic stem cells in a defined serum-free medium. Proc Nat/ Acad Sci USA 105: 13409-13414.

FURUE, M.K., TATEYAMA, D., KINEHARA, M., J. NA, OKAMOTO, T. and SATO, J.D. (2010). Advantages and difficulties in culturing human pluripotent stem cells in growth factor-defined serum-free medium. In vitro Cell.Dev.Biol. Animal 46: $573-576$

HAYNESWORTH, S.E., BABER, M.A. and CAPLAN, A.I. (1992). Cell surface antigens on human marrow-derived mesenchymal cells are detected by monoclonal antibodies. Bone 13: 69-80.

HOFFMAN, L.M. and CARPENTER, M.K. (2005). Characterization and culture of human embryonic stem cells. Nat Biotechno/23: 699-708.

ISHII, K., YOSHIDA, Y., AKECHI, Y., SAKABE, T., NISHIO, R., IKEDA, R., TERABAYASHI, K., MATSUMI, Y., GONDA, K., OKAMOTO, H. et al. (2008). Hepatic differentiation of human bone marrow-derived mesenchymal stem cells by tetracycline-regulated hepatocyte nuclear factor 3beta. Hepatology 48: 597606.

KULTERER, B., FRIEDL, G., JANDROSITZ, A., SANCHEZ-CABO, F., PROKESCH, A., PAAR, C., SCHEIDELER, M., WINDHAGER, R., PREISEGGER, K.H. and TRAJANOSKI, Z. (2007). Gene expression profiling of human mesenchymal stem cells derived from bone marrow during expansion and osteoblast differentiation. BMC Genomics 8: 70

KURODA, Y., KITADA, M., WAKAO, S., NISHIKAWA, K., TANIMURA, Y., MAKINOSHIMA, H., GODA, M., AKASHI, H., INUTSUKA, A., NIWA, A. et al (2010). Unique multipotent cells in adult human mesenchymal cell populations. Proc Natl Acad Sci USA 107: 8639-8643.

LENNON DP, H.S., BRUDER SP, JAISWAL N, CAPLAN AI. (1996). Human and animal mesenchymal progenitor cells from bone marrow: identfication of serum for optimal selection and proliferation. In vitro Cell Dev Biol Anim 32: 602-611.

LI, W.G. and XU, X.X. (2005). The expression of N-cadherin, fibronectin during chondrogenic differentiation of MSC induced by TGF-beta(1). Chin J Traumatol 8: 349-351.

METS, T. and VERDONK, G. (1981). In vitroaging of human bone marrow derived stromal cells. Mech Ageing Dev 16: 81-89.

MORI, T., KIYONO, T., IMABAYASHI, H., TAKEDA, Y., TSUCHIYA, K., MIYOSHI, S., MAKINO, H., MATSUMOTO, K., SAITO, H., OGAWA, S. et al. (2005). Combination of hTERT and bmi-1, E6, or E7 induces prolongation of the life span of bone marrow stromal cells from an elderly donor without affecting their neurogenic potential. Mol Cel/ Bio/25: 5183-5195.

NA, J., FURUE, M.K. and ANDREWS, P.W. (2010). Inhibition of ERK1/2 prevents neural and mesendodermal differentiation and promotes human embryonic stem cell self-renewal. Stem Cell Res 5: 157-169.

PANG, R., ZHANG, Y., PAN, X., GU, R., HOU, X., XIANG, P., LIU, Z., ZHU, X., HU, J., ZHAO, J. et al. (2010). Embryonic-like stem cell derived from adult bone marrow: immature morphology, cell surface markers, ultramicrostructure and differentiation into multinucleated fibers in vitro. Cell Mol Biol (Noisy-le-grand) 56 Suppl: OL1276-1285.

PITTENGER, M.F., MACKAY, A.M., BECK, S.C., JAISWAL, R.K., DOUGLAS, R. MOSCA, J.D., MOORMAN, M.A., SIMONETTI, D.W., CRAIG, S. and MARSHAK, D.R. (1999). Multilineage potential of adult human mesenchymal stem cells. Science 284: 143-147.

POCHAMPALLY, R.R., SMITH, J.R., YLOSTALO, J. and PROCKOP, D.J. (2004) Serum deprivation of human marrow stromal cells (hMSCs) selects for a subpopulation of early progenitor cells with enhanced expression of OCT-4 and other embryonic genes. Blood 103: 1647-1652.

ROUBELAKIS, M.G., PAPPA, K.I., BITSIKA, V., ZAGOURA, D., VLAHOU, A., PAPADAKI, H.A., ANTSAKLIS, A. and ANAGNOU, N.P. (2007). Molecular and 
proteomic characterization of human mesenchymal stem cells derived from amniotic fluid: comparison to bone marrow mesenchymal stem cells. Stem Cells Dev 16: 931-952.

SEKIYA, I., LARSON, B.L., SMITH, J.R., POCHAMPALLY, R., CUI, J.G. and PROCKOP, D.J. (2002). Expansion of human adult stem cells from bone marrow stroma: conditions that maximize the yields of early progenitors and evaluate their quality. Stem Cells 20: 530-541.

SHEVINSKY, L.H., KNOWLES, B.B., DAMJANOV, I. and SOLTER, D. (1982). Monoclonal antibody to murine embryos defines a stage-specific embryonic antigen expressed on mouse embryos and human teratocarcinoma cells. Cell 30: 697-705.

SHIMOMURA, T., YOSHIDA, Y., SAKABE, T., ISHII, K., GONDA, K., MURAI, R.,
TAKUBO, K., TSUCHIYA, H., HOSHIKAWA, Y., KURIMASA, A. et al. (2007). Hepatic differentiation of human bone marrow-derived UE7T-13 cells: Effects of cytokines and CCN family gene expression. Hepatol Res 37: 1068-1079.

TAKEUCHI, M., TAKEUCHI, K., KOHARA, A., SATOH, M., SHIODA, S., OZAWA, Y., OHTANI, A., MORITA, K., HIRANO, T., TERAI, M. et al. (2007). Chromosomal instability in human mesenchymal stem cells immortalized with human papilloma virus E6, E7, and hTERT genes. In vitro'Cell Dev Biol Anim 43: 129 138.

TSUTSUMI, S., SHIMAZU, A., MIYAZAKI, K., PAN, H., KOIKE, C., YOSHIDA, E. TAKAGISHI, K. and KATO, Y. (2001). Retention of multilineage differentiation potential of mesenchymal cells during proliferation in response to FGF. Biochem Biophys Res Commun 288: 413-419.

Further Related Reading, published previously in the Int. J. Dev. Biol.

See our recent Special Issue Placenta edited by Joan S. Hunt and Kent L. Thornburg at:

http://www.ijdb.ehu.es/web/contents. php?vol=54\&issue=2-3

Neurogenic differentiation of human conjunctiva mesenchymal stem cells on a nanofibrous scaffold Masoud Soleimani, Samad Nadri, Iman Shabani

Int. J. Dev. Biol. (2010) 54: 1295-1300

Epiblast-derived stem cells in embryonic and adult tissues

Maria P. De-Miguel, Francisco Arnalich-Montiel, Pilar Lopez-Iglesias, Alejandro Blazquez-Martinez and Manuel Nistal Int. J. Dev. Biol. (2009) 53: 1529-1540

Neurogenic and mitotic effects of dehydroepiandrosteroneon neuronal-competent marrow mesenchymal stem cells Esmaeil H. Shiri, Narges-Zare Mehrjardi, Mahmood Tavallaei, Saeid K. Ashtiani and Hossein Baharvand Int. J. Dev. Biol. (2009) 53: 579-584

Genetic and epigenetic instability of human bone marrow mesenchymal stem cells expanded in autologous serum or fetal bovine serum

John-Arne Dahl, Shivali Duggal, Neralie Coulston, Douglas Millar, JohnMelki, Aboulghassem Shahdadfar, Jan E. Brinchmann and Philippe Collas

Int. J. Dev. Biol. (2008) 52: 1033-1042

From bone marrow to therapeutic applications: different behaviour and genetic/epigenetic stability during mesenchymal stem cell expansion in autologous and foetal bovine sera?

Gaetana A. Tonti and Ferdinando Mannello

Int. J. Dev. Biol. (2008) 52: 1023-1032

5 yr ISI Impact Factor $(2009)=3.253$

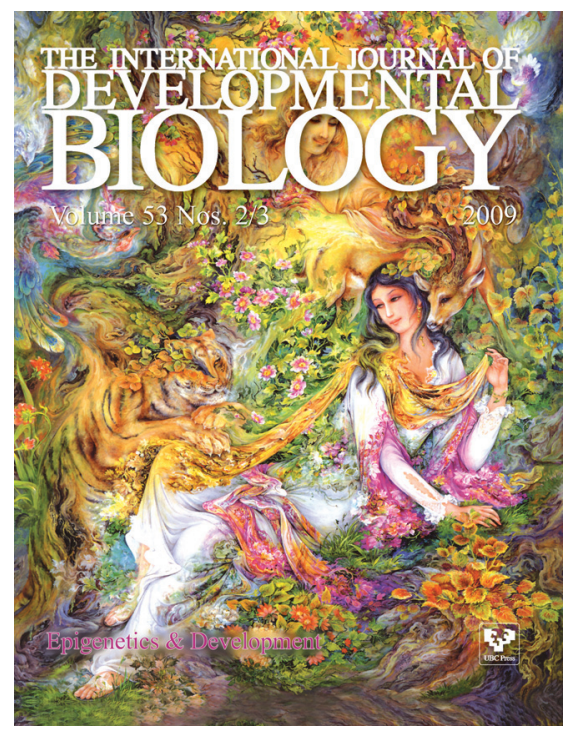

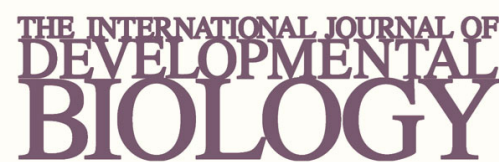

Volume 54 Nos. 6/7
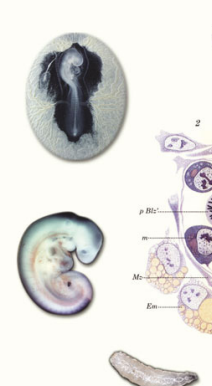

Developmental Hematopoiesis

Special Issue
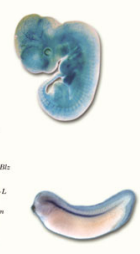

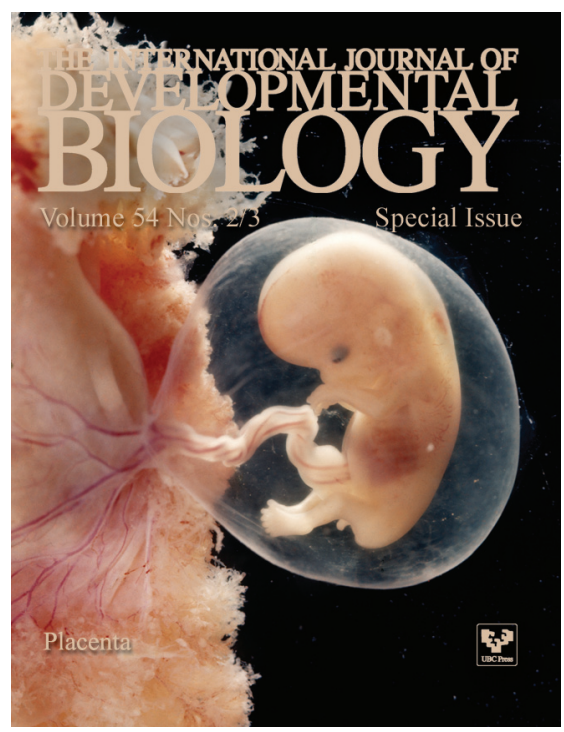

